\title{
Dramatic increase of third-generation cephalosporin-resistant E. coli in German intensive care units: secular trends in antibiotic drug use and bacterial resistance, 2001 to 2008
}

\author{
Elisabeth Meyer*1,2, Frank Schwab1,2, Barbara Schroeren-Boersch ${ }^{3}$ and Petra Gastmeier1,2
}

\begin{abstract}
Introduction: The objective of the present study was to analyse secular trends in antibiotic consumption and resistance data from a network of 53 intensive care units (ICUs).

Methods: The study involved prospective unit and laboratory-based surveillance in 53 German ICUs from 2001 through 2008. Data were calculated on the basis of proportions of nonduplicate resistant isolates, resistance densities (that is, the number of resistant isolates of a species per 1,000 patient-days) and an antimicrobial usage density (AD) expressed as daily defined doses (DDD) and normalised per 1,000 patient-days.

Results: Total mean antibiotic use remained stable over time and amounted to 1,172 DDD/1,000 patient-days (range 531 to 2,471). Carbapenem use almost doubled to an AD of 151 in 2008. Significant increases were also calculated for quinolone (AD of 163 in 2008) and third-generation and fourth-generation cephalosporin use (AD of 117 in 2008). Aminoglycoside consumption decreased substantially (AD of 86 in 2001 and 24 in 2008). Resistance proportions were as follows in 2001 and 2008, respectively: methicillin-resistant Staphylococcus aureus (MRSA) 26\% and 20\% ( $P=0.006$; trend test showed a significant decrease), vancomycin-resistant enterococcus (VRE) faecium 2.3\% and 8.2\% ( $P=0.008)$, third-generation cephalosporin (3GC)-resistant Escherichia. coli 1.2\% and 19.7\% ( $P<0.001)$, 3GC-resistant Klebsiella pneumoniae 3.8\% and 25.5\% ( $P<0.001)$, imipenem-resistant Acinetobacter baumannii 1.1\% and $4.5 \%(P=0.002)$, and imipenem-resistant $K$. pneumoniae $0.4 \%$ and $1.1 \%$. The resistance densities did not change for MRSA but increased significantly for VRE faecium and 3GC-resistant E. coli and K. pneumoniae. In 2008, the resistance density for MRSA was 3.73, 0.48 for VRE, 1.39 for 3GC-resistant E. coli and 0.82 for K. pneumoniae.
\end{abstract}

Conclusions: Although total antibiotic use did not change over time in German ICUs, carbapenem use doubled. This is probably due to the rise in 3GC-resistant E. coli and K. pneumoniae. Increased carbapenem consumption was associated with carbapenem-resistant $K$. pneumoniae carbapenemase-producing bacteria and imipenem-resistant $A$. baumannii.

\section{Introduction}

In recent years, an increased effort has been directed towards controlling antibiotic use and raising public awareness of the need for prudent use of antibiotics [1]. There are two main reasons for this. The first is ecological, in that antibiotics induce and select for bacterial resistance [2]. Resistance is meanwhile considered a global threat, and pathogens susceptible to antibiotics are

* Correspondence: elisabeth.meyer@charite.de

1 Institute of Hygiene and Environmental Medicine, Charité-University Medicine Berlin, Hindenburgdamm 27, 12203 Berlin, Germany Full list of author information is available at the end of the article considered a common good [3]. Antimicrobial drug effectiveness cannot be taken for granted and antimicrobials are increasingly attaining the status of nonrenewable resources. The second reason is economic, in that antibiotics account for a large portion of a hospital's pharmacy budget, and in the face of restricted financial resources are therefore a main target for cost savings [4]. Over the past decade, many surveillance efforts have drawn attention to this phenomenon [5-8].

The Surveillance System of Antibiotic Use and Bacterial Resistance in Intensive Care Units (SARI) is an ongo- 
ing project, launched in 2000 and initially funded by the German Government, that collects data from its network of intensive care units (ICUs) [9-12]. SARI focuses on the critically ill because antimicrobial use in ICUs is among the highest in the hospital setting and consumption often runs in parallel to the pattern seen for resistance.

The goal of the present study is to give an overview of changes in antibiotic consumption and resistance in a network of ICUs over a period of 8 years (2001 through 2008).

\section{Materials and methods}

SARI started in February 2000. Following a pilot phase, we first analysed data at the beginning of 2001. Data from 53 SARI ICUs were included in the analysis presented here: 21 of the 53 ICUs were interdisciplinary, 18 were surgical (of which four were neurosurgical) and 14 were medical. Most ICUs were located in hospitals affiliated with a university hospital $(\mathrm{n}=30)$ or in university hospitals $(\mathrm{n}=19)$. The median of hospital size was 790 beds (interquartile range 463 to 1,119 beds), and the median number of ICU beds was 12 (interquartile range 10 to 18 beds).

Data are fed back to the participants every 6 months. From 2001 through 2008, the numbers of ICUs reporting data to the project were $36,35,38,40,44,46,45$ and 45 , respectively. Forty-seven per cent of the ICUs sent data from all 8 years.

\section{Data collection}

Monthly data on antimicrobial use were obtained from the computerised pharmacy databases. Consumption that is, the antimicrobial usage density (AD) - was expressed as daily defined doses (DDD) and was normalised per 1,000 patient-days. The DDD are the standard adult daily dose of an antimicrobial agent for a 1-day treatment defined by the World Health Organisation (WHO ATC/DDD Index 2008) [13].

The ICUs indicated the number of isolates tested per month belonging to the following 13 sentinel bacterial species: Staphylococcus aureus, coagulase-negative staphylococci, Enterococcus faecalis, Enterococcus faecium, Pseudomonas aeruginosa, Enterobacter cloacae, Citrobacter spp., Serratia marcescens, Acinetobacter baumannii, Stenotrophomonas maltophilia, Streptococcus pneumoniae, Escherichia coli and Klebsiella pneumoniae. The susceptibility data were collected from the microbiology laboratory for these 13 pathogens regardless of whether they were associated with hospital-acquired or community-acquired infection or colonisation, or whether they were from clinical or surveillance cultures. Pathogens were specified as resistant by the clinical laboratory using interpretive criteria recommended by the German Industrial standard or CLSI. Copy strains - defined as an isolate of the same species showing the same susceptibility pattern throughout a period of 1 month in the same patient, no matter what the site of isolation - were excluded. Thirty-seven per cent of the SARI ICUs - 13 out of 35 SARI ICUs responded to a questionnaire on methicillin-resistant $S$. aureus (MRSA) management in 2008 - screened all patients for MRSA at admission. Questions on extended-spectrum $\beta$-lactamase (ESBL) screening were not included.

All data were anonymous and were collected in accordance with the German recommendations of good epidemiological praxis with respect to data protection [14]. As a federal law, the German Protection against Infection Act (Infektionsschutzgesetz $\$ 23$ ) regulates the prevention and management of infectious disease in humans. All hospitals are obliged to collect and analyse continuously nosocomial infections and resistant pathogens [15]. These routine data were reported to the National Reference Centre of the Surveillance of Nosocomial Infections. Ethical approval and informed consent were thus not required.

\section{Statistical analysis}

The proportion of resistant isolates was calculated by dividing the number of resistant isolates by the total number of the isolates of the same species tested against the corresponding antibiotic multiplied by 100 . The incidence density of resistant isolates (RD) was defined as being the number of resistant isolates per 1,000 patientdays. Differences in consumption and resistance by type of ICU were tested using the Kruskal-Wallis test. From 2001 through 2008, trends in resistance were analysed by regression analysis using aggregated 3-monthly data (24 time points) and trends in antibiotic use were analysed using monthly data (96 time points). We tested whether the linear regression coefficient was significantly different from zero.

The significance level was $P<0.05$ and all analyses were performed using EpiInfo 6.04 and SAS 9.2 (SAS Institute Inc., Cary, NC, USA).

\section{Results}

From 2001 through 2008, a total of 53 ICUs from 30 hospitals reported data to SARI covering 1,335,855 patientdays. The mean length of stay was 4.2 days in 2001 and 4.0 days in 2008. The rate of ventilated patients ranged between 45 and $49 \%$ over the 8-year period. Altogether, 121,548 pathogens (53\% of them Gram-positive) were isolated with a mean number of 91 pathogens per 1,000 patient-days.

Pooled mean antibiotic use over the 8-year period was $1,172 \mathrm{DDD} / 1,000$ patient-days; that is, each patient on average received 1.2 DDD. Antibiotic consumption ranged from 531 to $2,471 \mathrm{DDD} / 1,000$ patient-days 
(median 1,213 DDD/1,000 patient-days). The proportions of $\beta$-lactamase-sensitive penicillins, of penicillins with extended spectrum, of $\beta$-lactamase-resistant penicillins and of penicillins with $\beta$-lactamase inhibitor among the whole class of penicillins were $7.4 \%, 32.8 \%, 8.9 \%$, and $51.9 \%$, respectively (2001 to 2008). Figure 1 shows the heterogeneity of total antibiotic consumption and distribution over antibiotic classes in individual ICUs.

Total mean antibiotic use (without sulbactam) remained stable over time $(P=0.707)$. The AD was 1,180 $\mathrm{DDD} / 1,000$ patient-days in 2001 and was $1,167 \mathrm{DDD} /$ 1,000 patient-days in 2008 . There was no difference either in total antibiotic use or in the trend over time by type of ICU.

Within the antibiotic classes, carbapenem use almost doubled to an AD of 151 in 2008 (Figure 2). Carbapenem use and third-generation cephalosporin (3GC) resistance correlated significantly $(P=0.036$; correlation coefficient $=0.291)$. Significant increases were also calculated for quinolones and for third-generation and fourth-generation cephalosporin use. Consumption of the whole class of cephalosporins and penicillins, however, decreased significantly. Aminoglycosides showed the biggest decrease over time $(P<0.001)$. Macrolide use was significantly higher in medical ICUs, whereas second-genera- tion cephalosporin consumption was significantly lower in medical ICUs than in surgical or interdisciplinary ICUs.

The most striking result was the continuous increase of 3GC-resistant E. coli (\%), which equated to an almost 10fold increase within just 8 years. Vancomycin-resistant Enterococcus (VRE) faecium quadrupled between 2006 and 2008 (Table 1). In contrast, the proportion of MRSA even decreased and the resistance proportions of imipenem-resistant or ciprofloxacin-resistant $P$. aeruginosa revealed no trend at all.

Resistance differed by type of ICU: ciprofloxacin resistance in $P$. aeruginosa was significantly higher in medical and interdisciplinary ICUs than in surgical ICUs. In contrast, vancomycin resistance in E. faecium was significantly higher in medical ICUs.

It is also possible to demonstrate the different dynamics of resistant pathogens if the RD is used as a parameter for the burden of resistance (Figure 3). Although at 3.73 MRSA/1,000 patient-days MRSA still presented the highest burden of resistant pathogens in 2008, the burden of 3GC-resistant $E$. coli was a remarkable 1.39 ESBL isolates/1,000 patient-days. This means that in 2008 the RD of 3GC-resistant E. coli I was equivalent to more than one-third of the overall RD of MRSA. The burden of imi-

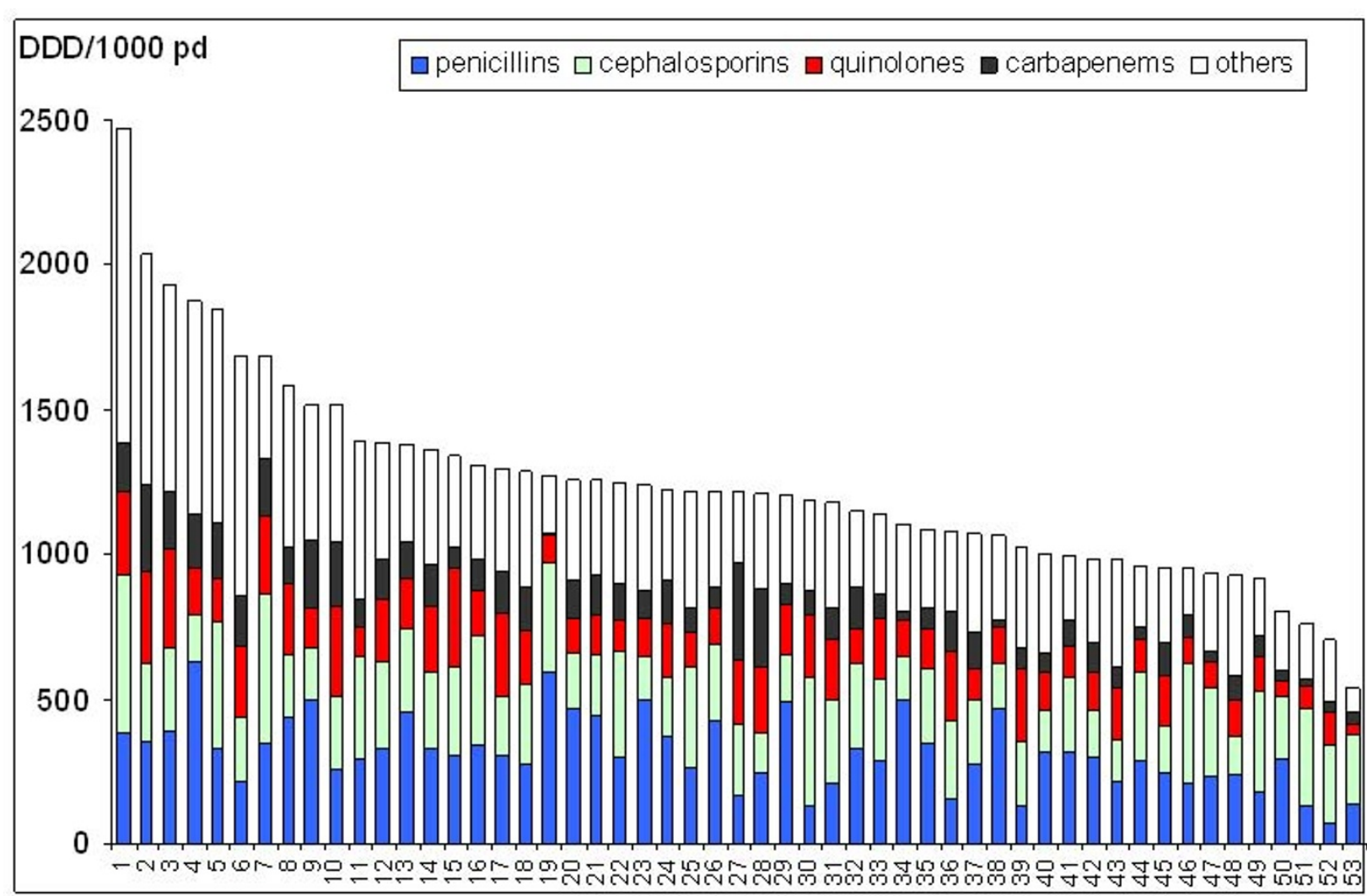

Figure 1 Antibiotic consumption in $\mathbf{5 3}$ German intensive care units from $\mathbf{2 0 0 1}$ to 2008. DDD, defined daily doses; pd, patient-days 


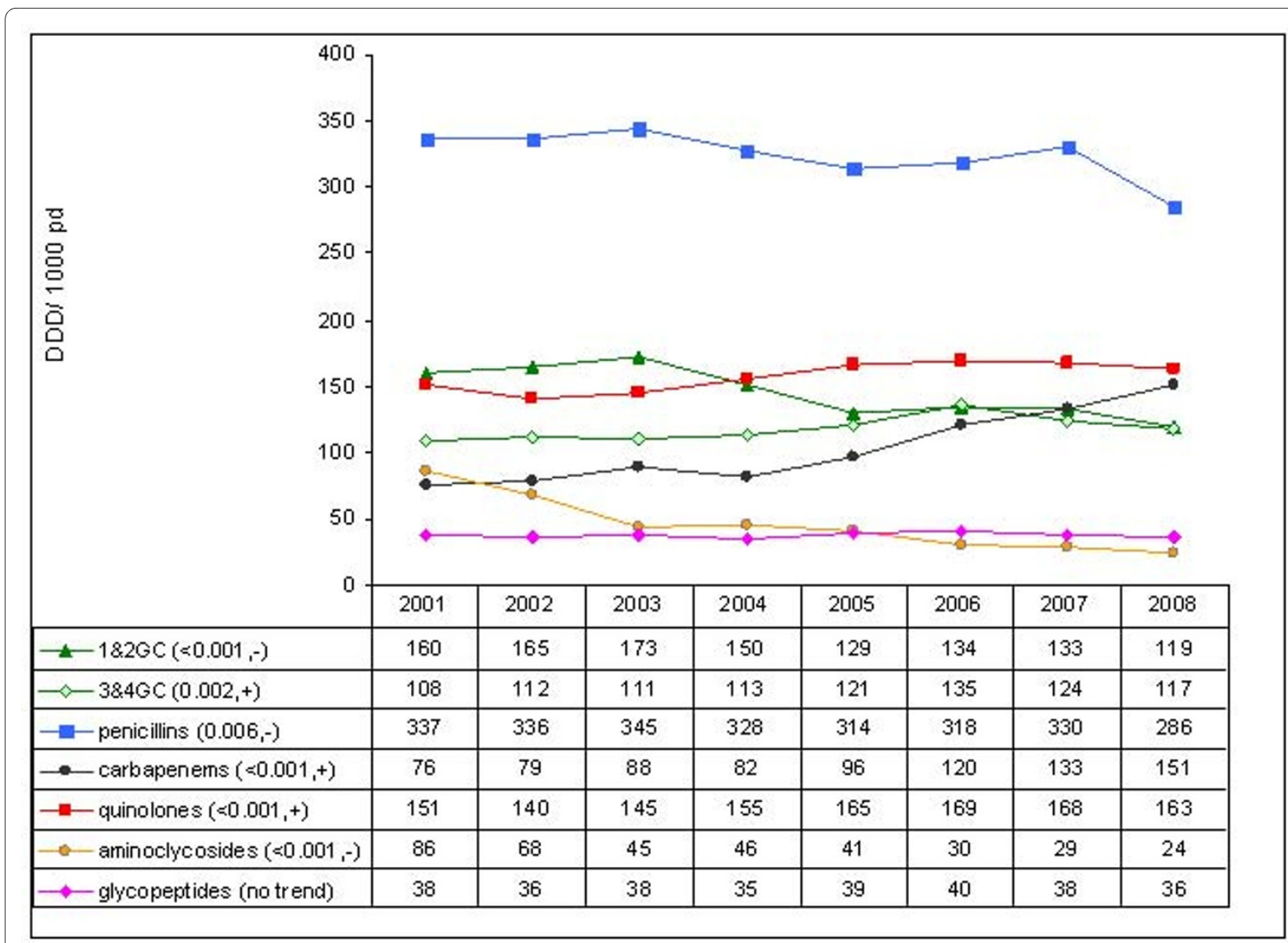

Figure $\mathbf{2}$ Change in antibiotic consumption in German intensive care units from 2001 to 2008. DDD, defined daily doses; pd, patient-days; $1 \& 2 \mathrm{GC}$, first-generation and second-generation cephalosporins; $3 \& 4 \mathrm{GC}$, third-generation and fourth-generation cephalosporins. $P$ value for the linear regression coefficient and trend (increase, + ; decrease, -) in parentheses.

penem-resistant K. pneumoniae was still low at 0.05 per 1,000 patient-days in 2008 , which corresponds to seven isolates from two separate ICUs.

Figure 4a, b shows the pooled mean and the median of carbapenem use and $3 \mathrm{GC}$ resistance in E. coli. Resistance started to increase in parallel in 2006, indicating that the increase was not only based on some outlier ICUs but affected almost all ICUs. Indeed, since 2006 just four ICUs have not been confronted with 3GC-resistant $E$. coli. The resistance proportions of 3GC-resistant E. coli in the other ICUs ranged from 2 to $24 \%$ and the RD from 0.1 to 4.6 . The burden of $3 \mathrm{GC}$-resistant $E$. coli even outnumbered the burden of MRSA in seven ICUs.

\section{Discussion}

The three main findings of this study are: that total antibiotic consumption remained stable from 2001 through 2008 with a mean use of 1.2 DDD per patient per ICUday; that the burden of resistance increased dramatically for 3GC-resistant E. coli and K. pneumoniae over 8 years, but not for MRSA; and that our data demonstrate the dangerous spiral of spread of resistance and antibiotic use - the increase in $3 \mathrm{GC}$ resistance, which indicates a rise in ESBL-producing bacteria, has been followed by a doubling of carbapenem use that, in turn, might now be followed by an increase in imipenem-resistant pathogens.

Antibiotic consumption varied widely by the factor of five, which may partially be explained by differences in patients and ICU characteristics, antibiotic policies or physicians' level of education. Although quantitative data must not be taken as qualitative parameters, the heterogeneity of antibiotic prescriptions might still indicate that antimicrobial use can be improved. We were able to show in three intervention studies that it was indeed possible to sustainably reduce antibiotic consumption in SARI ICUs by shortening the duration of treatment or revising antibiotic prophylaxis [16-18]. Generally, total median antibiotic use of 1,213 DDD/1,000 patient-days concurs with data from 35 ICUs in eight European countries in 2005, with a median of 1,254 DDD/1,000 patient-days (also 
Table 1: Pooled mean antimicrobial resistance of selected pathogens in German intensive care units (number of ICUs), 2001 to 2008

\begin{tabular}{|c|c|c|c|c|c|c|c|c|c|}
\hline $\begin{array}{l}\text { Resistant pathogen (number tested } \\
\text { against each antimicrobial) }\end{array}$ & $\begin{array}{l}2001 \\
(n=36)\end{array}$ & $\begin{array}{l}2002 \\
(n=35)\end{array}$ & $\begin{array}{l}2003 \\
(n=38)\end{array}$ & $\begin{array}{l}2004 \\
(n=40)\end{array}$ & $\begin{array}{l}2005 \\
(n=44)\end{array}$ & $\begin{array}{l}2006 \\
(n=46)\end{array}$ & $\begin{array}{l}2007 \\
(n=45)\end{array}$ & $\begin{array}{l}2008 \\
(n=45)\end{array}$ & Pvalue* \\
\hline $\begin{array}{l}\text { Methicillin-resistant } \\
\text { Staphylococcus aureus }(27,446)\end{array}$ & 26.0 & 22.4 & 20.9 & 19.5 & 22.6 & 22.2 & 20.6 & 19.5 & $0.006(-)$ \\
\hline $\begin{array}{l}\text { Vancomycin-resistant } \\
\text { Enterococcus faecium }(6,331)\end{array}$ & 2.3 & 1.2 & 1.2 & 5.4 & 5.4 & 2.2 & 3.6 & 8.2 & $0.008(+)$ \\
\hline $\begin{array}{l}\text { 3GC-resistant } \\
\text { Escherichia coli }(18,425)\end{array}$ & 1.2 & 1.8 & 2.9 & 3.8 & 3.7 & 5.1 & 11.1 & 10.5 & $<0.001(+)$ \\
\hline $\begin{array}{l}\text { Ciprofloxacin-resistant } \\
\text { Escherichia coli }(16,184)\end{array}$ & 8.3 & 11.9 & 14.1 & 16.5 & 18.2 & 16.4 & 20.9 & 24.2 & $<0.001(+)$ \\
\hline $\begin{array}{l}\text { 3GC-resistant } \\
\text { Klebsiella pneumoniae }(7,457)\end{array}$ & 3.8 & 12.2 & 5.9 & 6.5 & 6.5 & 6.5 & 10.4 & 15.1 & $<0.007(+)$ \\
\hline $\begin{array}{l}\text { Imipenem-resistant } \\
\text { Pseudomonas aeruginosa }(10,468)\end{array}$ & 24.0 & 22.8 & 23.5 & 23.8 & 22.0 & 24.4 & 27.0 & 25.5 & No trend \\
\hline $\begin{array}{l}\text { Ciprofloxacin-resistant } \\
\text { Pseudomonas aeruginosa }(11,590)\end{array}$ & 19.7 & 18.4 & 15.6 & 19.5 & 17.4 & 19.3 & 17.0 & 16.0 & No trend \\
\hline $\begin{array}{l}\text { Imipenem-resistant } \\
\text { Acinetobacter baumannii }(2,014)\end{array}$ & 1.1 & 0.7 & 1.0 & 2.5 & 6.3 & 20.3 & 9.7 & 4.5 & $0.002(+)$ \\
\hline $\begin{array}{l}\text { Imipenem-resistant } \\
\text { Klebsiella pneumoniae }(5,732)\end{array}$ & 0.4 & 0.2 & 0.3 & 0.3 & 0.0 & 0.3 & 0.4 & 1.1 & NA \\
\hline
\end{tabular}

ranging widely from 348 to 4,992 DDD/1,000 patientdays) [19]. In Swedish ICUs, antibiotic use increased significantly from 1,245 DDD/1,000 patient-days in 1999 to $1,510 \mathrm{DDD} / 1,000$ patient-days in 2003. In these ICUs, antibiotic prescribing was empiric and adequate $[20,21]$. It can be assumed that antibiotic therapy is also widely empiric in SARI ICUs because the mean ICU stay was only 4.0 days. Empiric antibiotic therapy should be timely and adequate; however, it will normally be broad in the critically ill. The changed resistance situation - that is, the increase in 3GC-resistant E. coli - was associated with a doubling in carbapenem use.

The European Antimicrobial Resistance Surveillance System described resistance against 3GC in E. coli as the most dynamic expansion of multidrug-resistant pathogens in the entire region [22]. Although in 2008 just under one-half of European countries (14 of 33) reported their resistance levels against $3 \mathrm{GC}$ to be under $5 \%$, since 2004 the proportion of $3 \mathrm{GC}$ resistance has increased in 19 European countries. In general, a large percentage of ESBL-producing pathogens are now being imported into hospitals and ICUs [23-25]. Known risk factors inside and outside the hospital include use especially of broad-spectrum cephalosporins and quinolones, which, in some ICUs at least, are the workhorses of antibiotic therapy [26-28]. Use of these antibiotic classes might also contribute to the selection of ESBLs, to the persistence of pre- dominant ESBL clones and to the probable dissemination of conjugative plasmids among strains. Limiting administration of these antibiotics to patients in which other therapeutic alternatives according to evidence-based guidelines are not possible is therefore part of many antibiotic stewardship programmes.

A shift toward greater carbapenem usage harbours the risk of greater selection of carbapenem resistance and is associated with permeability mutations in strains already producing ESBLs or other potent $\beta$-lactamases [29]. This is already happening, especially in Klebsiella. Current reports indicate that $K$. pneumoniae carbapenemases (KPC) are widespread in China, Israel, Greece, South America, and the USA [29,30]. Fortunately, KPC-producing bacteria are still rare in Western Europe and Northern Europe. Although not yet broadly reflected in our data - only two ICUs encountered imipenem-resistant $K$. pneumoniae in 2008 - it is to be expected that such strains will also be increasingly encountered in European ICUs, because it has been shown that high level carbapenemresistant KPC-producing bacteria may be selected during imipenem and meropenem therapy [31]. In contrast, the increase in 3GC-resistant $E$. coli has now affected most ICUs and is therefore unlikely to be a problem caused by the selection pressure of antibiotic therapy in the individual ICU. If the import into the ICU and the burden of multiresistant pathogens continues to increase, however, 


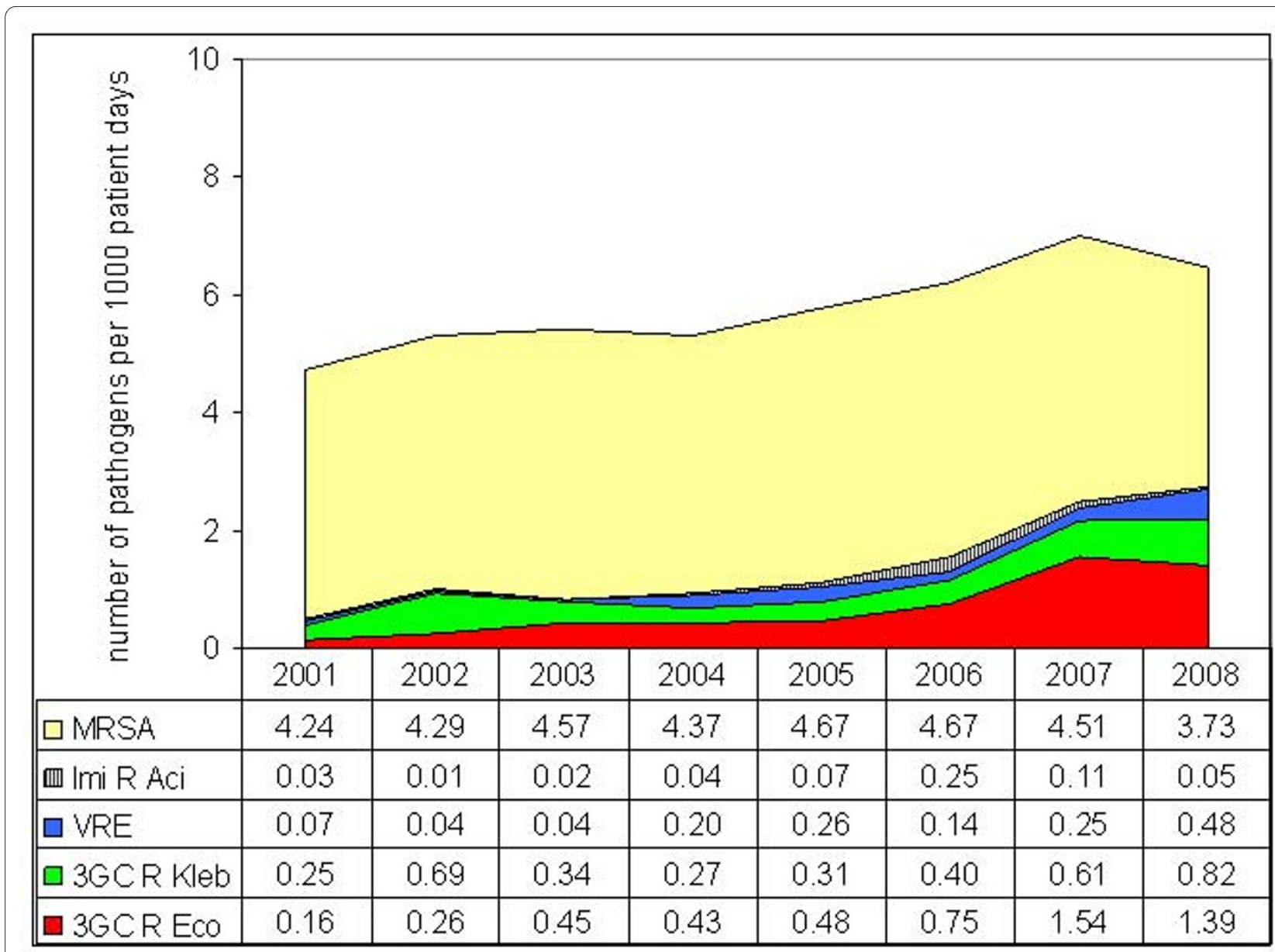

Figure $\mathbf{3}$ Change in burden of resistance of multidrug-resistant pathogens from 2001 to 2008. MRSA, methicillin-resistant Staphylococcus aureus; Imi R Aci, imipenem-resistant Acinetobacter baumannii; VRE, vancomycin-resistant Enterococcus faecium; 3GC R Kleb, third-generation cephalosporin-resistant Klebsiella pneumoniae; 3GC R Eco, third-generation cephalosporin-resistant Escherichia coli.

adopting appropriate infection control strategies becomes paramount to prevent the transmission to other patients. Besides the basic set of infection control measures, early identification by screening and accommodating patients with multidrug-resistant pathogens in single rooms or cohort isolation is recommended [32].

The spread and emergence of resistance is multifaceted; it is not driven by antibiotic use alone, but is, among other things, also influenced by clonal spread of strains, by resistance mechanisms that might differ by species, the human and environmental reservoir, and by infection control strategies, including screening policies. We hypothesise that these factors at least partly explain why MRSA resistance did not increase over the study period but VRE did, why imipenem-resistant $K$. pneumoniae increased but imipenem-resistant $P$. aeruginosa did not, or why ciprofloxacin-resistant $E$. coli increased yet ciprofloxacin-resistant $P$. aeruginosa did not.

For instance, cumulative German prevalence data from 2007 show that the percentage of ciprofloxacin-resistant
E. coli was even higher in the outpatient setting than in ICU patients (29.2\% vs. $21.9 \%)$ [33]. This indicates that quinolone-resistant strains of $E$. coli are imported to ICUs through the massive selective pressure of quinolones prescribed in the outpatient setting in Germany; outpatient antibiotic use accounts for $85 \%$ of total antibiotic use [34]. Furthermore, use of quinolones in therapy and prophylaxis, especially in commercial poultry farming, contributes to the emergence of resistant organisms in the human population, especially in pathogens having their reservoir in the gut. In contrast, the natural reservoir of $A$. baumannii is unknown and $A$. baumannii is rarely found on the human skin or in the environment. Higgins and colleagues presented global data on carbapenem-resistant $A$. baumannii suggesting that carbapenem resistance developed after or during the spread of the clonal lineages [35]. They explained that clonal lineages originated worldwide in at least eight distinct loci and then spread to new locations, possibly through patient transfer. If clonal spread is probably responsible 
(a)

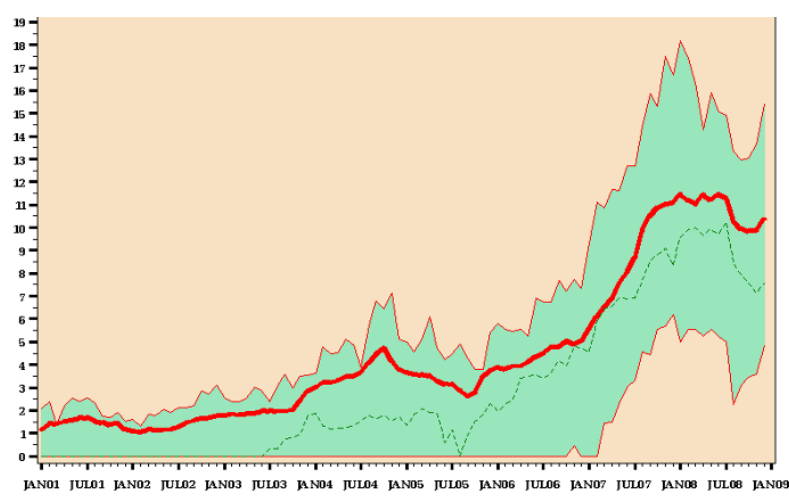

(b)

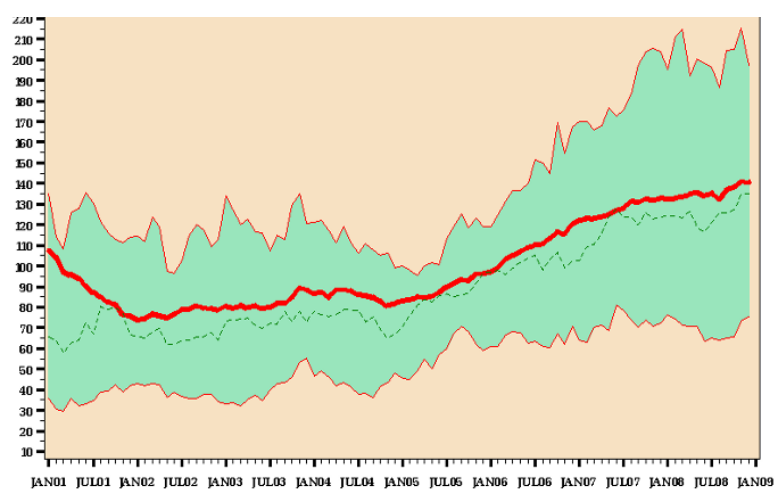

Figure 4 Third-generation cephalosporin-resistant Escherichia coli and carbapenem use from 2001 to 2008. (a) Percentage of third-generation cephalosporin-resistant (3GC) Escherichia coli. The pooled mean (solid line) and the median (dotted line) run almost parallel to one another. The sharp increase in 3CG-resistant E. coli starts in 2006 and affects almost all intensive care units (ICUs). The interquartile range (shaded area) shows that 50\% of all ICUs had resistance proportions between 5 and 15\% in 2008. (b) Carbapenem use. The pooled mean (solid line) and the median (dotted line) run almost parallel to one another. In most ICUs the increase in carbapenem use also starts in 2006. The interquartile range (shaded area) shows that carbapenem use in 50\% of all ICUs ranged between 70 and 190 daily defined doses (DDD)/1,000 patient-days (pd) in 2008.

for the spread of carbapenem-resistant A. baumannii, then $A$. baumannii infections may indicate a serious infection-control problem. Although there was a temporal association between increases in carbapenem use and imipenem resistance in A. baumannii in our study, it does not prove a causal relationship.

The present study has several limitations. Whereas the ecological study design can lead to the formation of a hypothesis, ultimately it does not prove a causative relationship - which a patient-based study design is able to establish. Potential confounders such as antimicrobial stewardship interventions (for example, the feedback of the data to the ICUs is a type of intervention) or promotion of hand hygiene could have influenced antibiotic use and antimicrobial resistance in individual ICUs. The number of ICUs participating in SARI increased from 36 to 53 , with $47 \%$ of the ICUs reporting data over the 8 -year period. ICUs that joined recently might therefore have had different antimicrobial usage patterns, as well as a different antimicrobial resistance situation. Outbreaks might have influenced pooled mean resistance data. World Health Organisation DDD do not always correctly reflect the actual prescribed daily dose [36,37]. This inconsistency does not invalidate the systematic approach of the World Health Organisation, and therefore ICUs should use the DDD to make national and international comparisons of their antibiotic use.

\section{Conclusions}

Disturbingly, ICUs have little in reserve to control multidrug resistance among Gram-negative bacteria [38]. We consider five points to be of paramount importance.
Firstly, ICUs must ensure proper detection in their laboratories of extended-spectrum $\beta$-lactamases among KPCproducing Enterobacteriaceae clinical isolates [39]. Secondly, treatment options for infections with multiresistant Gram-negative bacteria and KPC-producing organisms are limited. Besides tigecycline, therefore, old antibiotics like aminoglycosides, fosfomycin, colistin and rifampicin will have to be re-employed. Thirdly, treatment duration should be as short as is clinically feasible to reduce selection pressure [40]. Fourthly, screening on admission, as already established for MRSA, might be considered to address the increasing import of resistant pathogens into the ICU and to minimise the risk of transmission [24]. Finally, infection control - especially hand hygiene, the purpose of which is to prevent person-toperson spread - is elementary and crucial.

\section{Key messages}

- The burden of resistance increased dramatically for 3GC-resistant E. coli and K. pneumoniae, which indicates a rise in ESBL-producing bacteria.

- This increase has been followed by a doubling of carbapenem use from 2001 through 2008.

- Greater carbapenem use harbours the risk of greater selection of carbapenem resistance and is associated with permeability mutations in strains already producing ESBLs or KPCs.

- Because treatment options for infections with multiresistant Gram-negative bacteria and KPC-producing organisms are limited, besides tigecycline, old antibiotics such as aminoglycosides, fosfomycin, and colis- 
tin with or without rifampicin will have to be reemployed.

- Adopting appropriate infection control strategies becomes paramount to prevent transmission to other patients.

\section{Abbreviations}

AD: antimicrobial usage density; DDD: daily defined doses; ESBL: extendedspectrum $\beta$-lactamase; 3GC: third-generation cephalosporin; ICU: intensive care unit; KPC: Klebsiella pneumoniae carbapenemase; MRSA: methicillin-resistant Staphylococcus aureus; RD: resistance densities; SARI: Surveillance of Antibiotic Use and Bacterial Resistance in Intensive Care Units; VRE: vancomycinresistant enterococcus.

\section{Competing interests}

The authors declare that they have no competing interests.

\section{Authors' contributions}

All authors have contributed substantially to the submitted work and have read and approved the final manuscript. EM wrote the manuscript, FS analysed the data, BSB collected the data and PG revised the manuscript critically.

\section{Acknowledgements}

The authors thank Deborah Lawrie-Blum for help in preparing the manuscript.

\section{Author Details}

'Institute of Hygiene and Environmental Medicine, Charité-University Medicine Berlin, Hindenburgdamm 27, 12203 Berlin, Germany, ${ }^{2}$ National Reference Centre for the Surveillance of Nosocomial Infections, Hindenburgdamm 27, 12203 Berlin, Germany and ${ }^{3}$ Institute of Environmental Health Sciences, University Medical Center Freiburg, Breisachstraße 115B, 79106 Freiburg, Germany

Received: 23 October 2009 Revised: 10 December 2009

Accepted: 14 June 2010 Published: 14 June 2010

\section{References}

1. WHO Global Strategy for Containment of Antimicrobial Resistance [http://www.who.int/drugresistance/WHO Global Strategy English.pdf

2. Livermore DM: Bacterial resistance: origins, epidemiology, and impact. Clin Infect Dis 2003, 36:S11-S23.

3. Foster KR, Grundmann H: Do we need to put society first? The potential for tragedy in antimicrobial resistance. PLoS Med 2006, 3:e29.

4. Maragakis LL, Perencevich EN, Cosgrove SE: Clinical and economic burden of antimicrobial resistance. Expert Rev Anti Infect Ther 2008 6:751-763.

5. Bronzwaer SL, Cars O, Buchholz U, Molstad S, Goettsch W, Veldhuijzen IK Kool JL, Sprenger MJ, Degener JE: A European study on the relationship between antimicrobial use and antimicrobial resistance. Emerg Infect Dis 2002, 8:278-282.

6. Jones ME, Draghi DC, Thornsberry C, Karlowsky JA, Sahm DF, Wenzel RP: Emerging resistance among bacterial pathogens in the intensive care unit - a European and North American Surveillance study (2000-2002). Ann Clin Microbiol Antimicrob 2004, 3:14.

7. Molstad S, Erntell M, Hanberger H, Melander E, Norman C, Skoog G, Lundborg CS, Soderstrom A, Torell E, Cars O: Sustained reduction of antibiotic use and low bacterial resistance: 10-year follow-up of the Swedish Strama programme. Lancet Infect Dis 2008, 8:125-132.

8. Vander Stichele RH, Elseviers MM, Ferech M, Blot S, Goossens H: Hospital consumption of antibiotics in 15 European countries: results of the ESAC Retrospective Data Collection (1997-2002). J Antimicrob Chemother 2006, 58:159-167.

9. Meyer E, Gastmeier P, Schwab F: The burden of multiresistant bacteria in German intensive care units. J Antimicrob Chemother 2008 62:1474-1476

10. Meyer E, Jonas D, Schwab F, Rueden H, Gastmeier P, Daschner FD: Design of a surveillance system of antibiotic use and bacterial resistance in German intensive Care units (SARI). Infection 2003, 31:208-215.

11. Meyer E, Schwab F, Gastmeier P, Jonas D, Rueden H, Daschner FD: Methicillin-resistant Staphylococcus aureus in German intensive care units during 2000-2003: data from project SARI (Surveillance of Antimicrobial Use and Antimicrobial Resistance in Intensive Care Units). Infect Control Hosp Epidemiol 2006, 27:146-154.

12. Surveillance der Antibiotika-Anwendung und der bakteriellen Resistenzen auf Intensivstationen [http://www.nrz-hygiene.de/sari/ sari.htm]

13. WHO Collaborating Centre for Drug Statistics Methodology ATC/DDD Index [http://www.whocc.no/atc ddd index/]

14. Leitlinien und Empfehlungen zur Sicherung von Guter Epidemiologischer Praxis (GEP) [http://www.rki.de/cln 169/ nn 205212/DE/Content/GBE/EpidemiologischeMethoden/ Empfehlungen/ empfehlungen pdf1,templateld=raw,property=publicationFile.pdf/ empfehlungen pdf1.pdf]

15. Gesetz zur Verhütung und Bekämpfung von Infektionskrankheiten beim Menschen [http://bundesrecht.juris.de/ifsg/ 23.html]

16. Meyer E, Buttler J, Schneider C, Strehl E, Schroeren-Boersch B, Gastmeier P, Ruden H, Zentner J, Daschner FD, Schwab F: Modified guidelines impact on antibiotic use and costs: duration of treatment for pneumonia in a neurosurgical ICU is reduced. J Antimicrob Chemother 2007, 59:1148-1154

17. Meyer E, Lapatschek M, Bechtold A, Schwarzkopf G, Gastmeier P, Schwab $F$ : Impact of restriction of third generation cephalosporins on the burden of third generation cephalosporin resistant $K$. pneumoniae and E. coli in an ICU. Intensive Care Med 2009, 35:862-870.

18. Meyer E, Schwab F, Pollitt A, Bettolo W, Schroeren-Boersch B, Trautmann $M$ : Impact of a change in antibiotic prophylaxis on total antibiotic use in a surgical intensive care unit. Infection 2010, 38:19-24.

19. Hanberger H, Arman D, Gill H, Jindrak V, Kalenic S, Kurcz A, Licker M Naaber P, Scicluna EA, Vanis V, Hanberger H, Arman D, Gill H, Jindrak V, Kalenic S, Kurcz A, Licker M, Naaber P, Scicluna EA, Vanis V, Walther SM: Surveillance of microbial resistance in European Intensive Care Units: a first report from the Care-ICU programme for improved infection control. Intensive Care Med 2009, 35:91-100.

20. Erlandsson M, Burman LG, Cars O, Gill H, Nilsson LE, Walther SM, Hanberger $\mathrm{H}$ : Prescription of antibiotic agents in Swedish intensive care units is empiric and precise. Scand J Infect Dis 2007, 39:63-69.

21. Hanberger H, Burman LG, Cars O, Erlandsson M, Gill H, Nilsson LE, Nordlinder D, Walther SM: Low antibiotic resistance rates in Staphylococcus aureus, Escherichia coli and Klebsiella spp but not in Enterobacter spp and Pseudomonas aeruginosa: a prospective observational study in 14 Swedish ICUs over a 5-year period. Acto Anaesthesio/ Scand 2007, 51:937-941.

22. European Antimicrobial Resistance Surveillance System annual report 2008 [http://www.rivm.nl/earss/Images/EARSS\%202008 final tcm6165020.pdf]

23. Harris AD, McGregor JC, Johnson JA, Strauss SM, Moore AC, Standiford HC, Hebden JN, Morris JG: Risk factors for colonization with extendedspectrum $\beta$-lactamase-producing bacteria and intensive care unit admission. Emerg Infect Dis 2007, 13:1144-1149.

24. Meyer E, Serr A, Schneider C, Utzolino S, Kern WV, Scholz R, Dettenkofer M: Should we screen patients for extended-spectrum $\beta$-lactamaseproducing enterobacteriaceae in intensive care units? Infect Control Hosp Epidemiol 2009, 30:103-105.

25. Rodriguez-Bano J, Navarro MD, Romero L, Martinez-Martinez L, Muniain MA, Perea EJ, Perez-Cano R, Pascual A: Epidemiology and clinical features of infections caused by extended-spectrum $\beta$-lactamase-producing Escherichia coli in nonhospitalized patients. J Clin Microbiol 2004 42:1089-1094

26. Arpin C, Quentin C, Grobost F, Cambau E, Robert J, Dubois V, Coulange L, Andre $C$ : Nationwide survey of extended-spectrum $\beta$-lactamaseproducing Enterobacteriaceae in the French community setting. $J$ Antimicrob Chemother 2009, 63:1205-1214.

27. Ben-Ami R, Rodriquez-Bano J, Arslan H, Pitout JD, Quentin C, Calbo ES, Azap OK, Arpin C, Pascual A, Livermore DM, Ben-Ami R, Rodriguez-Bano J, Arslan H, Pitout JD, Quentin C, Calbo ES, Azap OK, Arpin C, Pascual A, Livermore DM, Garau J, Carmeli Y: A multinational survey of risk factors for infection with extended-spectrum $\beta$-lactamase-producing enterobacteriaceae in nonhospitalized patients. Clin Infect Dis 2009, 49:682-690

28. Kaier K, Frank U, Hagist C, Conrad A, Meyer E: The impact of antimicrobial drug consumption and alcohol-based hand rub use on the emergence 
and spread of extended-spectrum beta-lactamase-producing strains: a time-series analysis. J Antimicrob Chemother 2009, 63:609-614.

29. Nordmann P, Cuzon G, Naas T: The real threat of Klebsiella pneumoniae carbapenemase-producing bacteria. Lancet Infect Dis 2009, 9:228-236.

30. Kitchel B, Sundin DR, Patel JB: Regional dissemination of KPC-producing Klebsiella pneumoniae. Antimicrob Agents Chemother 2009,

53:4511-4513

31. Hong T, Moland ES, Abdalhamid B, Hanson ND, Wang J, Sloan C, Fabian D, Farajallah A, Levine J, Thomson KS: Escherichia coli: development of carbapenem resistance during therapy. Clin Infect Dis 2005, 40:e84-e86.

32. Siegel JD, Rhinehart E, Jackson M, Chiarello L: Management of multidrugresistant organisms in health care settings, 2006. Am J Infect Control 2007, 35:S165-S193.

33. Kresken M, Hafner D, Schmitz FJ, Wichelhaus TA: Resistenzsituation bei klinisch wichtigen Infektionserregern gegenüber Antibiotika in Deutschland und im mitteleurop,,ischen Raum. [http://www.p-eg.org/ag resistenz/main.htm].

34. GERMAP 2008 Antibiotika-Resistenz und -Verbrauch [http:// www.bvl.bund.de/cln 007/DE/08 Presselnfothek/

00 doks downloads/

Germap 2008,templateld=raw,property=publicationFile.pdf/ Germap 2008.pdf]

35. Higgins PG DC, Hackel M, Seifert H: Global spread of carbapenemresistant Acinetobacter baumannii. J Antimicrob Chemother 2010, 65:233-238

36. de With K, Bestehorn H, Steib-Bauert M, Kern WV: Comparison of defined versus recommended versus prescribed daily doses for measuring hospital antibiotic consumption. Infection 2009, 37:349-352.

37. Muller A, Monnet DL, Talon D, Henon T, Bertrand X: Discrepancies between prescribed daily doses and WHO defined daily doses of antibacterials at a university hospital. Br J Clin Pharmacol 2006, 61:585-591

38. Livermore DM: Has the era of untreatable infections arrived? J Antimicrob Chemother 2009, 64(Suppl 1):i29-i36.

39. Tsakris A, Poulou A, Themeli-Digalaki K, Voulgari E, Pittaras T, Sofianou D, Pournaras S, Petropoulou D: Use of boronic acid disk tests to detect extended-spectrum $\beta$-lactamases in KPC carbapenemase-possessing enterobacteriaceae clinical isolates. J Clin Microbiol 2009, 47:3420-3426.

40. Chastre J, Wolff M, Fagon JY, Chevret S, Thomas F, Wermert D, Clementi E, Gonzalez J, Jusserand D, Asfar P, Chastre J, Wolff M, Fagon JY, Chevret S, Thomas F, Wermert D, Clementi E, Gonzalez J, Jusserand D, Asfar P, Perrin $D$. FieuX F. Aubas S: Comparison of 8 vs 15 days of antibiotic therapy for ventilator-associated pneumonia in adults: a randomized trial. JAMA 2003, 290:2588-2598.

\section{doi: $10.1186 /$ cc9062}

Cite this article as: Meyer et al., Dramatic increase of third-generation cephalosporin-resistant E. coli in German intensive care units: secular trends in antibiotic drug use and bacterial resistance, 2001 to 2008 Critical Care 2010, 14:R113
Submit your next manuscript to BioMed Central and take full advantage of:

- Convenient online submission

- Thorough peer review

- No space constraints or color figure charges

- Immediate publication on acceptance

- Inclusion in PubMed, CAS, Scopus and Google Scholar

- Research which is freely available for redistribution

Submit your manuscript at www.biomedcentral.com/submit
C Biomed Central 